\title{
Dual Detection of Procalcitonin and C-reactive Protein with an Up-converting Nanoparticle Based Lateral Flow Assay
}

\author{
Nan Zhan, Yang Zhou, Laibao MeI, Yuwang HaN, ${ }^{\dagger}$ and Hongman ZhanG ${ }^{\dagger}$ \\ College of Chemistry and Molecular Engineering, Nanjing Tech University, Nanjing 211816, China
}

\begin{abstract}
Procalcitonin (PCT) and C-reactive protein (CRP) are significant complementary inflammatory markers, and their simultaneous detection is of substantial value. In this article, a rapid, simple and cost-effective method for the dual quantitative detection of PCT and CRP in serum is discussed. Two UCNPs of similar size and morphology, but with a different emission spectrum, were prepared for the simultaneous detection of PCT and CRP by lateral flow assay (LFA) technology in a direct method. With the developed dual test strips and signal read system, the assay results present a limit of detection (LOD) of $0.12 \mathrm{ng} / \mathrm{mL}$ and $0.24 \mu \mathrm{g} / \mathrm{mL}$ for PCT and CRP, respectively. In addition, both of the coefficients of variation and positive and negative concordance rates for PCT or CRP are well compared with those of the traditional method. The dual detection of PCT and CRP have shown great application potential in medical diagnosis and treatment guidance.
\end{abstract}

Keywords Dual detection, immunoassay, point-of-care testing, layer-by-layer assembly, lateral flow assay, inflammatory markers

(Received July 30, 2018; Accepted October 9, 2018; Advance Publication Released Online by J-STAGE October 19, 2018)

\section{Introduction}

C-reactive protein (CRP) and procalcitonin (PCT) have become increasingly important biomarkers because of their reference value in the diagnosis and treatment guidance of many diseases. ${ }^{1,2}$ CRP is an acute-phase reaction protein that reacts with lysophosphatidylcholine expressed on the surface of dead or dying cells, and it activates, complements, and promotes phagocytosis and immunomodulation. ${ }^{3}$ In various acute or chronic infections, tissue damage, malignant tumours, myocardial infarction, surgical trauma, radiation damage, etc., CRP rapidly rises within several hours and returns to normal after recovery from the disease. ${ }^{4-6} \mathrm{CRP}$ can be used as one of the first indicators for the observation of acute inflammation, tissue damage and therapeutic effects. PCT is the precursor of the hormone calcitonin, which was first identified by Deftos et al. in the 1970s. ${ }^{7}$ The level of PCT in the blood stream of healthy individuals is almost undetectable $(0.01 \mu \mathrm{g} / \mathrm{L}){ }^{8}$ However, PCT can be produced by several cell types and many organs in response to pro-inflammatory stimuli, in particular by bacterial products, and the concentration rises to more than $100 \mu \mathrm{g} / \mathrm{L}$ during severe infection. ${ }^{9}$

Although PCT has higher sensitivity and specificity in predicting pyelonephritis ${ }^{10}$ and systemic inflammatory response syndrome (SIRS) ${ }^{11}$ than CRP does, the level of PCT does not increase significantly with viral or non-infectious inflammations. CRP levels may increase in non-infectious tissue necrosis, but not in severe hepatitis or autoimmune disease infections. Each

$\dagger$ To whom correspondence should be addressed. E-mail: hanyw@njtech.edu.cn (Y. H.); hmzhang@njtech.edu.cn (H. Z.) of the physiological indicators has its own limitations, and multiple detection could improve the diagnostic accuracy. ${ }^{12}$ Therefore, simultaneous and fast detection of PCT and CRP is necessary and of great significance for clinical diagnosis and guiding medication. ${ }^{13}$

Many methods have been developed for measuring PCT and CRP, ${ }^{14}$ such as ELISA, ${ }^{15,16}$ immunoturbidimetry, and the electrochemical method. ${ }^{17,18}$ These methods are expensive for sophisticated instrument, have low accuracy or are time consuming due to tedious operation, whereas the lateral flow assay (LFA) method is less expensive, faster and more userfriendly.

LFA is a chromatography technology based on a specific immune reaction. Up-converting nanoparticles (UCNPs) has been widely used as reporters in LFA. Compared with colloidal gold, quantum dots, magnetic beads, and fluorescent dyes, UCNPs have many advantages, such as strong fluorescent intensity, sharp emission bandwidths, a low autofluorescence background, and a high resistance to photobleaching. ${ }^{19}$ The upconverting phosphor technology-based lateral flow assay (UPTLFA) has been widely used in immunoassays, and it is suitable for multiple detection as well. ${ }^{20}$

Multiple detection is much more difficult than is single detection, not only for the improvement demand of instruments, but also for cross interference caused by non-specific interactions and spectral interference. Many efforts have been put into multiple detection, including pathogens, microorganisms, medicinal metabolites, and food and environmental monitoring. ${ }^{20-23}$ For example, Liang et al. ${ }^{24}$ synthesized single UCNPs for the multiple detection of bacteria with green and red emissions, which may have problems with non-specific adsorption. Another difficulty of the simultaneous detection of PCT and CRP is the substantial differences in concentration 

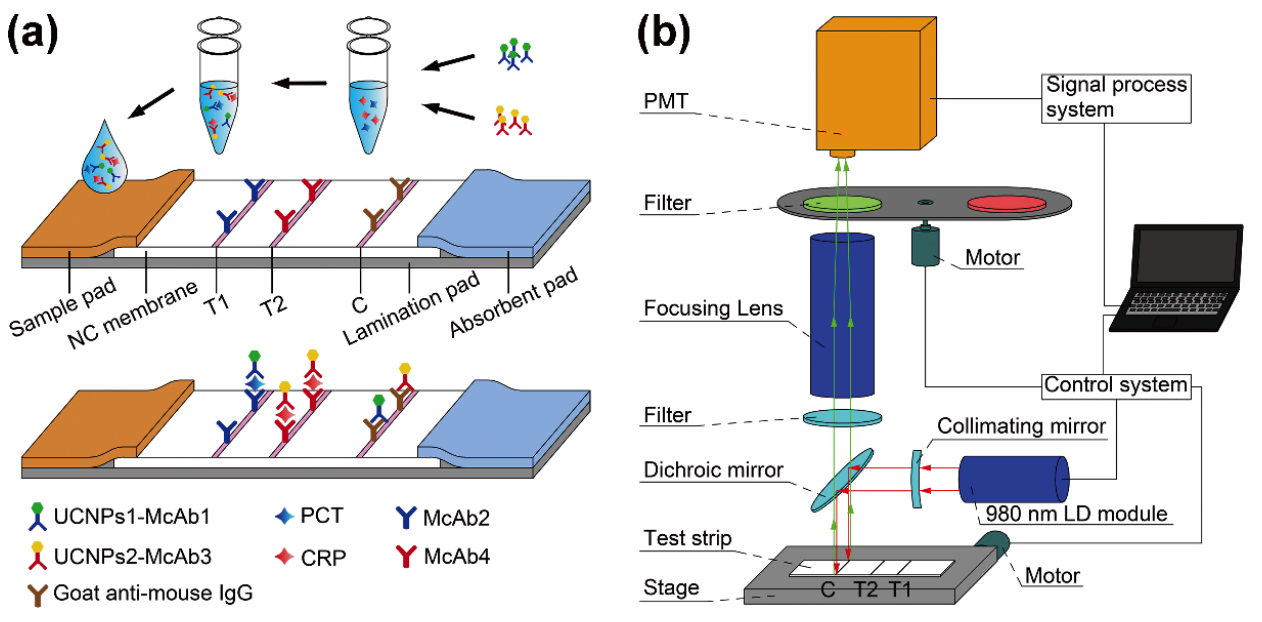

Fig. 1 Graphical illustration of the lateral flow assay strip for dual detection (a) and the signal read system (b).

levels (ng/mL for PCT and $\mu \mathrm{g} / \mathrm{mL}$ for CRP). Qi et al. ${ }^{25}$ developed the method of dual-quantum-dots (QDs) labelled LFA to detect PCT and CRP, but the QDs tended to be photobleached and the spectra of the QDs overlapped heavily.

It is reported in this paper that PCT and CRP were simultaneously detected with different kinds of UCNPs using the direct LFA method. The $\mathrm{K}^{+}$doped $\mathrm{Na}_{0.8} \mathrm{~K}_{0.2} \mathrm{YF}_{4}$ : $\mathrm{Yb}, \mathrm{Er} @$ $\mathrm{Na}_{0.8} \mathrm{~K}_{0.2} \mathrm{YF}_{4}$ (UCNPs1) and $\mathrm{Na}_{0.8} \mathrm{~K}_{0.2} \mathrm{YF}_{4}: \mathrm{Yb}, \mathrm{Tm} @ \mathrm{Na}_{0.8} \mathrm{~K}_{0.2} \mathrm{YF}_{4}$ (UCNPs2) with core-shell structure were selected for their strong and well-separated emission bands. ${ }^{19,26,27}$ Layer-by-layer (LBL) self-assembly technology was used to modify the UCNPs. Clinical samples were tested and analyzed, the results of which indicated a good relationship between the signal and the corresponding antigen's concentration.

\section{Experiment and Methods}

\section{Chemicals and materials}

Yttrium chloride $\left(\mathrm{YCl}_{3}\right)$, ytterbium chloride $\left(\mathrm{YbCl}_{3}\right)$, erbium chloride $\left(\mathrm{ErCl}_{3}\right)$, thulium chloride $\left(\mathrm{TmCl}_{3}\right)$, ammonium fluoride $\left(\mathrm{NH}_{4} \mathrm{~F}\right)$, sodium hydroxide $(\mathrm{NaOH})$, potassium hydroxide $(\mathrm{KOH})$, methanol $\left(\mathrm{CH}_{3} \mathrm{OH}\right)$, and cyclohexane $\left(\mathrm{C}_{6} \mathrm{H}_{12}\right)$ were purchased from Sun Chemical Technology(Shanghai) Co., Ltd. 1-Octadecene (ODE), oleic acid (OA), cetyl trimethyl ammonium bromide (CTAB), poly(sodium 4-styrenesulfonate) (PSS, $M_{\mathrm{w}}$ 70000), poly(allylamine hydrochloride) (PAH, $M_{\mathrm{w}}$ 17500), poly(acrylic acid) (PAA, $M_{\mathrm{w}}$ 2000), 1-ethyl-3-(3dimethylaminopropyl)carbodiimide hydrochloride (EDC), $\mathrm{N}$-hydroxysuccinimide (NHS), and 2-(N-morpholino)ethanesulfonic acid (MES) were obtained from Sigma-Aldrich. Antibodies against PCT (McAb1, McAb2) and CRP (McAb3, McAb4) were produced from mouse and were kindly provided by Norman Biological Technology Co., Ltd. (Nanjing). Goat antimouse IgG, lamination pad, nitrocellulose (NC) membrane, sample pad and absorbent pad were purchased from JY Biotech Co., Ltd. (Shanghai). Other reagents and solvents were of analytical grade and were used without further purification.

\section{Equipment}

Transmission electron microscopy (TEM) images of UCNPs before and after modification were obtained with a JEM-2100F Field Emission Electron Microscope (Japan Electronics Co.,
Japan). The particle size distribution and zeta potential were measured by NanoBrook Omni (Brookhaven Instruments, USA). The fluorescence spectra of UCNPs were measured from an F97XP fluorospectro photometer (Lengguang Tech, China) that was excited with a 980-nm semiconductor laser (LOS-BLD-0980-2W-C/P, Hi-Tech Optoelectronics, China). A chemiluminescence immunoassay analyzer (NRM-CL-200, Norman Biological Technology, China) and corresponding detection kits were used for quantifying PCT and CRP. The results were taken as the truth value.

\section{Preparation of the UCNPs probes}

$\mathrm{K}^{+}$-doped $\mathrm{Na}_{0.8} \mathrm{~K}_{0.2} \mathrm{YF}_{4}: \mathrm{Yb}, \mathrm{Er} @ \mathrm{Na}_{0.8} \mathrm{~K}_{0.2} \mathrm{YF}_{4}$ (UCNPs1) was prepared using a typical solvothermal method, ${ }^{28-31}$ as described in Supporting Information. The synthesized nanoparticles were highly hydrophobic because of the long alkyl chain of adsorbed OA. ${ }^{32}$ To be applied in the aqueous phase bioassay, a layer-bylayer assembly of polyelectrolytes was used to create hydrophilic surface chemistry. ${ }^{33}$ UCNPs were dispersed in $9 \mathrm{~mL}$ chloroform $(5 \mathrm{mg} / \mathrm{mL})$ and then dropped into a flask containing a $90-\mathrm{mL}$ CTAB aqueous solution $(10 \mathrm{mg} / \mathrm{mL})$. The mixture was then stirred for $1 \mathrm{~h}$ and warmed up to $70^{\circ} \mathrm{C}$ for approximately $2 \mathrm{~h}$ in order to remove chloroform. The remaining solvent was centrifuged and washed three times, and the resulting particle was denoted as UCNPs@CTAB. In the following, the second layer PSS was assembled. Then, a $5 \mathrm{~mL}$ Tris- $\mathrm{HCl}$ buffer (pH 8.0) and $75 \mu \mathrm{L} 10 \mathrm{mg} / \mathrm{mL}$ PSS were added into the obtained UCNPs@CTAB particles, shaken for $40 \mathrm{~min}$. Then, the UCNPs assembled PSS was achieved after being recentrifuged and washed. After that, PAH and PAA were assembled in the same way. The final PAA coating provided nanoparticles with functional groups capable of being conjugated with proteins. The classical EDC- and NHS-mediated method was used for the conjugation of UCNPs with the corresponding antibodies (Supporting Information). The blocking of the antibody-coupled UCNPs with BSA not only eliminated the remaining active groups, but also provided a proper surface environment to enhance the stability of the particles against other biomolecules in serum.

Taking into account the concentration differences of PCT and CRP in the clinic, the fluorescence intensity of the two UCNPs and the response sensitivity of PMT in the different spectra band (the responsivity of PMT at $545 \mathrm{~nm}$ is approximately 2.5 -times 

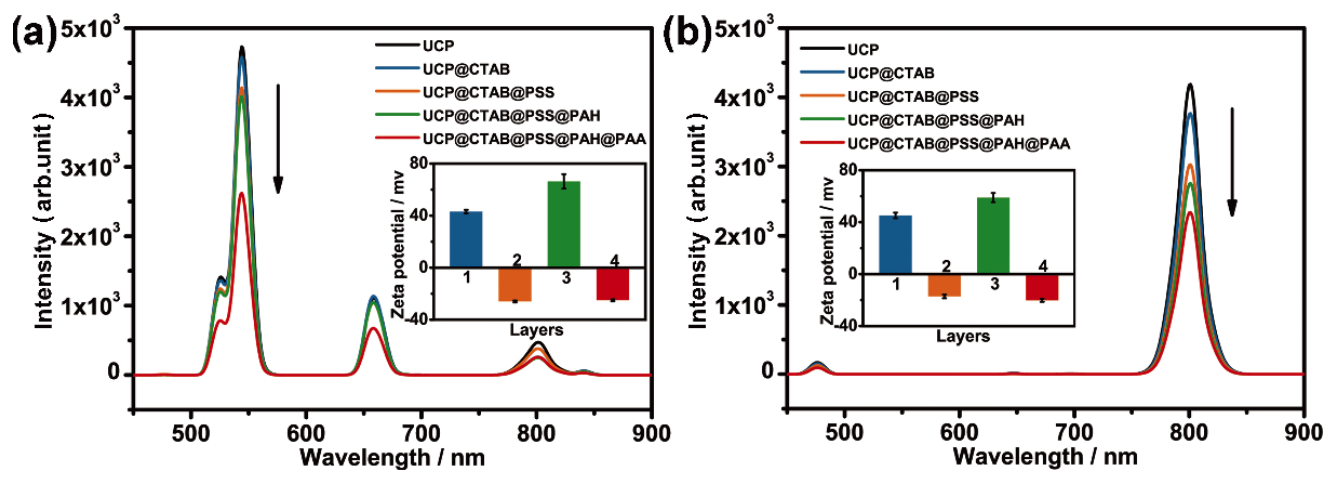

Fig. 2 Up-converting fluorescence spectra and zeta potentials of UCNPs1 (a) and UCNPs2 (b) after each LBL step.

that at $800 \mathrm{~nm}$ ), UCNPs1 was chosen to detect PCT and UCNPs2 was used for CRP.

\section{Preparation of test strips and the signal read system}

The test strips were manufactured by laminating the $\mathrm{NC}$ membrane, sample pad and absorbent pad on the lamination pad in the proper order and each part overlapped by $1 \mathrm{~mm}$, as shown in Fig. 1(a). The strips for single and dual detection were all prepared. The capture antibody $(1.2 \mathrm{mg} / \mathrm{mL})$ and goat antimouse $\operatorname{IgG}(1.5 \mathrm{mg} / \mathrm{mL})$ were dispensed in a line on the $\mathrm{NC}$ membrane at a rate of $1 \mu \mathrm{L} / \mathrm{cm}$ and were denoted as the $\mathrm{T}$ and $\mathrm{C}$ lines, respectively. In addition to the $\mathrm{C}$ line, the dual detection strips were dispensed with two kinds of capture antibodies as the $\mathrm{T} 1$ and $\mathrm{T} 2$ lines. The laminated plates were cut into strips with $4 \mathrm{~mm}$ width and stored in a dryer for future use.

The luminescence signal read system was constructed in our laboratory (Fig. 1(b)). A 980-nm fiber laser was used as the excitation light. The UCNPs-linked conjugates on the test or control lines were excited, and the emitted light reached the photomultiplier tube (PMT) before being filtered by the proper filters $(545 \mathrm{~nm}$ center wavelength for UCNPs 1 and $800 \mathrm{~nm}$ for UCNPs2; both of the bandwidths were $30 \mathrm{~nm}$ ). Then, the light signal was transformed into an electrical signal and transferred to a personal computer. The light intensity distribution along the test strip was recorded by a scanning strip via the movement of the stage.

\section{Immunoassay and generation of standard curves}

The tested sample was mixed with relevant antibodyconjugated UCNPs and was incubated for a period of time before it was dropped onto the sample pad. Immunoreactions between the analytes with UCNPs-labeled antibodies were completed and formed immune complexes. Then, the immune complexes would migrate along the strip by a capillary force offered by the absorbent pad. As a result, the targeted analytes would further form an immune sandwich complex with a corresponding capture antibody, which was fixed on the T1 or $\mathrm{T} 2$ line, while the remaining labelled antibodies would be captured by the control line. Quantification was conducted based on the relationship between the analyte content and the signal ratio of the $\mathrm{T}$ line to $\mathrm{C}$ line $\left(S_{\mathrm{T}} / S_{\mathrm{C}}\right)$.

The human serums quantified by CLIA were legally collected by Norman Biological Technology Co., Ltd. from hospitals, and were used in the following experiments. The serum with the highest content of PCT $(9.81 \mathrm{ng} / \mathrm{mL})$ and another sample with CRP $(100 \mu \mathrm{g} / \mathrm{mL})$ were chosen as the original samples and were serially diluted with HEPES ( $\mathrm{pH} 7.4,20 \mathrm{mM}$ ); then, the solutions were used to build standard curves for single detection. A sample with $11.827 \mathrm{ng} / \mathrm{mL}$ PCT and $129.78 \mu \mathrm{g} / \mathrm{mL}$ CRP was used to generate the dual detection calibration curves.

\section{Performance of the dual detection and method comparison}

To assess the accuracy and reproducibility of the established dual UPT-LFA detection method, samples with low, medium and high concentration levels were tested repeatedly with the same batch of strips. The intra-coefficient of variation (intra$\mathrm{CV}$ ) was calculated from 10 parallel samples of the same group, and the inter-coefficient of variation (inter-CV) was calculated from 3 groups. The dual detection was compared with a commercially available CLIA method (quantified by a chemiluminescence immunoassay analyzer NRM-CL-200) in 49 fresh serum specimens obtained from patients. The BlandAltman method was used for statistical data analysis.

\section{Results and Discussion}

\section{Characterization of UCNPS}

The transmission electron microscopy (TEM) images shown in Supporting Information, Figs. S1(a) and S1(b) revealed that the synthesized UCNPs1 and UCNPs2 were of a similar size and morphology. The two particles were all in the hexagonal phase, which has a stronger emission intensity than that of cubic crystal. ${ }^{34}$ Additionally, the particles were well dispersed with a size range of about $50-100 \mathrm{~nm}$, according to the dynamic light scattering (DLS) results (all of the PDI $<0.16$, Fig. S1), which give strong luminescence and acceptable migration resistance. ${ }^{24}$ In the assay process, these properties indicate a low detection limit and more accurate detection.

To be applied in the bioassay, UCNPs are supposed to be water dispersible and biocompatible. However, the synthesized UCNPs were coated by oleic acid. Layer-by-layer (LBL) selfassembly technology was used to modify UCNPs because of the simple operation, high stability and biocompatibility. Meanwhile, this method permits the coated UCNPs of different shapes and sizes, with uniform layers of diverse composition as well as controllable thickness. ${ }^{35}$ The UCNPs became charge carried and hydrophilic after being assembled with CTAB by a hydrophobic interaction between the long alkyl chains. Then, the dispersibility and stability of the particles were enhanced after being adsorbed with PSS, PAH, and PAA successively by electrostatic interaction.

Figures S1(c) and S1(d) in Supporting Information shows that the UCNPs became less angular than that before, and that 

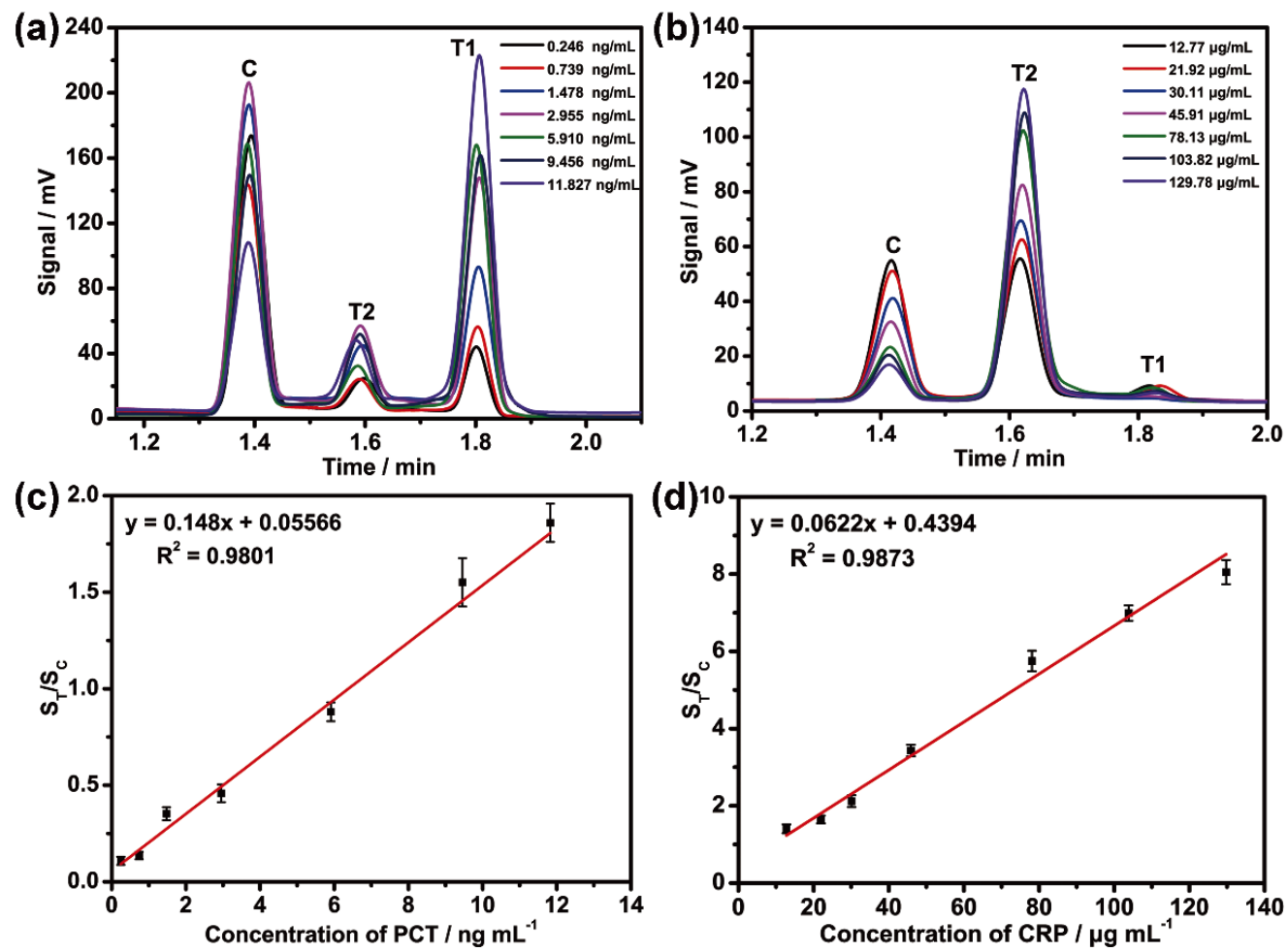

Fig. 3 Immunochromatographic spectra of dual detection of PCT (a), CRP (b) and the standard curves of PCT (c) and CRP (d).

the size had no significant vibrations after modification, which indicated that the modified layers were very thin. We observed that the zeta potential of the UCNPs after each layer underwent modification (embedded in Fig. 2) varied between positive and negative after each self-assembly and finally became negative, which proved the successful assembly with each of CTAB, PSS, PAH and PAA. The multi-layer modification ${ }^{36}$ and the strong interlayer interaction ${ }^{37}$ permit the stability of particles. Therefore, the UCNPs could effectively conjugate with proteins through a reaction between the carboxyl and amino groups.

The fluorescence spectrum of the two UCNPs in Fig. 2 showed that the UCNPs1 and UCNPs2 had different maximum emission peaks, which guaranteed their simultaneous detection. Moreover, the intensity of UCNPs declined with increased coating layers. The adsorbed polyelectrolyte may have little influence on the intensity,,$^{38,39}$ and the main reason is the inevitable loss during multiple washing and resuscitation. After LBL modification, the fluorescent intensity was attenuated by $45 \%$ for UCNPs 1 and by $44 \%$ for UCNPs 2 .

\section{Interferences}

The cross-interferences of PCT and CRP were studied by adding $100 \mu \mathrm{g} / \mathrm{mL}$ CRP when detecting PCT and adding $10 \mathrm{ng} / \mathrm{mL}$ PCT when detecting CRP. At the same time, samples with a different content of PCT and CRP were investigated using the interferences of different endogenous substances. The results in Fig. S2 (Supporting Information) show that PCT and CRP had no cross-interferences and that none of the endogenous substances had notable interference on the detection of these two biomarkers. Moreover, the results proved that there was strong binding and high specificity between the antibodies and antigens of both PCT and CRP.

\section{Detection with developed method of dual UPT-LFA}

A problem in the dual detection of PCT and CRP is their large concentration difference in the clinical samples. It was reported that two different formats were introduced: the double antibody sandwich for PCT and the competitive inhibition method for CRP. ${ }^{40}$ Nevertheless, this method would limit the detection range of the assay. Another scheme was binding low-affinity phosphocholine to CRP and thus forming a low-sensitivity sandwich ${ }^{41}$ but it showed high coefficients of variation. In this paper, a proportional linear relationship, rather than a logarithmic linear relationship, of PCT and CRP was obtained, which gives high accuracy and stability.

The resulting spectrograms and standard curves of dual detection are exhibited in Fig. 3. We observed that when PCT was detected, the signal that should not have appeared at the T2 line in theory had a clear peak (Fig. 3(a)). One reason that may account for this phenomenon is that, compared to that of PCT, the concentration of CRP was so high that a large amount of the sandwich immunocomplex of CRP formed at the T2 line and blocked the flow path of the remaining unreacted McAb1UCNPs 1 that were supposed to migrate to the $\mathrm{C}$ line. This result meant that the signal appearing at the $\mathrm{T} 2$ line should be added to the $\mathrm{C}$ line because both of the signals were generated by the unreacted immune complex UCNPs1-McAb1. Similarly, there was a small peak that could be ignored at the T1 line when detecting CRP, which may have arisen from the emission of either the UCNPs1 at $800 \mathrm{~nm}$ or the blocked sandwich immunocomplex of CRP.

\section{Limit of the detection and linear ranges of single and dual UPT-} LFA

All of the samples were tested three times. The results of single detection are shown in Fig. S5. With the single tests, the obtained calibration curves were $y=0.18884 x+0.08617$ 
$\left(R^{2}=0.9882\right)$ for PCT and $y=0.06113 x+0.51887 \quad\left(R^{2}=\right.$ $0.9919)$ for CRP. The obtained limit of detection (LOD) was calculated from $\mathrm{LOD}=K S_{0} / S$, where there is a value of 3 for $K$, $S_{0}$ represents the standard deviation of 11 negative samples, and $S$ represents the slope of the standard curve. The LODs for PCT and CRP were estimated to be $0.10 \mathrm{ng} / \mathrm{mL}$ and $0.25 \mu \mathrm{g} / \mathrm{mL}$, respectively.

For dual detection, the calibration curve came out with the regression equation $y=0.148 x+0.05566\left(R^{2}=0.9801\right)$ and $y=0.06222 x+0.4394\left(R^{2}=0.9873\right)$ for PCT and CRP, respectively. The LODs were $0.12 \mathrm{ng} / \mathrm{mL}$ for PCT and $0.24 \mu \mathrm{g} / \mathrm{mL}$ for CRP, which were similar to the LODs with single detection. Meanwhile, the linearity ranges were $0.12-11.827 \mathrm{ng} / \mathrm{mL}$ for PCT and $0.24-129.781 \mu \mathrm{g} / \mathrm{mL}$ for CRP. The LOD of this method was comparable with that of other multi-assays (Table 1)

Table 1 Comparison of other methods in the PCT and/or CRP detection

\begin{tabular}{llllc}
\hline \multicolumn{1}{c}{ Method } & Analyte & Detection limit & Time & Ref. \\
\hline Dual-QDs LFA & PCT & $0.3 \mathrm{ng} \mathrm{mL}^{-1}$ & $20 \mathrm{~min}$ & 25 \\
& CRP & $50 \mathrm{ng} \mathrm{mL}^{-1}$ & & \\
Protein chip & PCT & $0.078 \mathrm{ng} \mathrm{mL}^{-1}$ & $4 \mathrm{~h}$ & 40 \\
& CRP & $3 \mu \mathrm{g} \mathrm{mL}^{-1}$ & & \\
On-chip microassay & PCT & $0.2 \mathrm{ng} \mathrm{mL}^{-1}$ & $>45 \mathrm{~min}$ & 41 \\
& CRP & $2 \mu \mathrm{g} \mathrm{mL}^{-1}$ & & \\
ELISA & CRP & $0.4 \mathrm{ng} \mathrm{mL}^{-1}$ & $<30 \mathrm{~min}$ & 16 \\
QDs LFA & CRP & $0.3 \mathrm{ng} \mathrm{mL}^{-1}$ & $3 \mathrm{~min}$ & 42 \\
Electrochemical & PCT & $0.36 \mathrm{pg} \mathrm{mL}^{-1}$ & $2 \mathrm{~h}$ & 18 \\
Electrochemiluminescene & PCT & $3.4 \mathrm{pg} \mathrm{mL}^{-1}$ & $>45 \mathrm{~min}$ & 43 \\
UPT-LFA & PCT & $0.12 \mathrm{ng} \mathrm{mL}^{-1}$ & $35 \mathrm{~min}$ & This \\
& CRP & $0.24 \mu \mathrm{g} \mathrm{mL}^{-1}$ & & work \\
\hline
\end{tabular}

and the ranges of detection could be expected to be larger because the Hook effect has not been detected for the available serum samples with highest concentration.

\section{Accuracy and reproducibility of dual UPT-LFA}

In addition to the LODs and linearity ranges, the high precision and reliability of the test methods were significant and necessary as well, especially in regard to medical assay. To assess the accuracy and reproducibility of the established dual UPT-LFA detection method, samples with low, medium and high concentration levels were tested repeatedly with the same batch of strips. Serum samples with concentrations of $0.10,1.13$, and $8.27 \mathrm{ng} / \mathrm{mL}$ for PCT and 4.24, 25.87, and $95.64 \mu \mathrm{g} / \mathrm{mL}$ for CRP (quantified by CLIA) were chosen. The calculated results (shown in Table S1, Supporting Information) indicated that the intra-coefficient of variation (intra-CV) ranged from $4.46-7.88 \%$ and that the inter-coefficient of variation (inter$\mathrm{CV}$ ) ranged from $6.78-9.16 \%$ for PCT, as well as an intra-CV of $2.97-5.95 \%$ and, inter-CV of $6.53-8.89 \%$ for CRP. All of the variations were within $10 \%$, and thus demonstrate good accuracy and reproducibility. Compared with the on-chip array design, ${ }^{39}$ the dual UPT-LFA method was much more superior.

\section{Method comparison}

More research work was conducted to evaluate the potential application of this method in clinical testing. To assess the concordance between this method and commercial chemiluminescence, 49 serum samples were simultaneously assayed by CLIA and the developed UPT-LFA. The results from CLIA were defined as being true positive or true negative, and were compared with the results from UPT-LFA. As shown in Table S2 (Supporting Information), there were $93.1 \%$ positive and $95 \%$ negative concordance rates for PCT, and $97.37 \%$ and
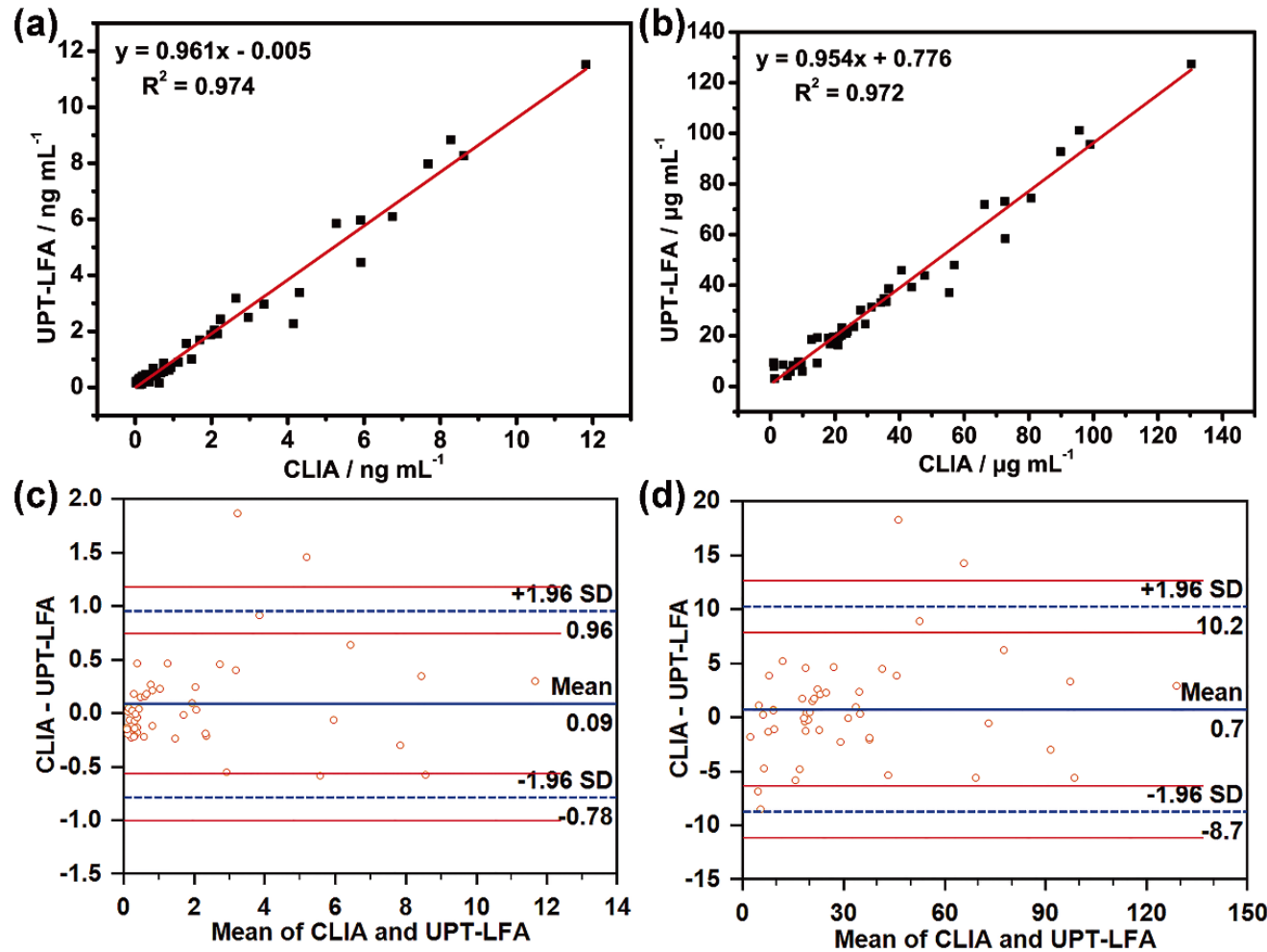

Fig. 4 Comparison of the test results between CLIA and dual UPT-LFA for PCT (a) and CRP (b) and the Bland-Altman of the dual UPT-LFA and CLIA for PCT (c) and CRP (d). 
$100 \%$ for CRP, respectively. The correlations between UPTLFA and CLIA of the two targets were evaluated by the 49 paired results, which indicated that (Figs. 4(a) and 4(b)) the results of the two methods were of high similarity, with $R^{2}=$ 0.974 and 0.972 for PCT and CRP, respectively.

Bland-Altman analysis ${ }^{44}$ (Figs. 4(c) and 4(d)) of the paired results demonstrated that, among the 49 samples, 2 samples were not within the limits and accounted for $4.08<5 \%$. The detection biases of the dual UPT-LFA and CLIA methods were 0.09 and 0.7 , respectively. Therefore, the dual UPT-LFA showed a potential clinical application for the simultaneous quantitative detection of PCT and CRP in patient serum samples.

\section{Conclusions}

In this reporter, a rapid and simple LFA method based on UCNPs marked probes for simultaneously detecting PCT and CRP in a direct way was established. The proper UCNPs with different emission bands were prepared and modified with simple and reliable solvothermal and LBL methods, respectively. With the developed test strips and reassembled reader, the results of dual detection showed a good linear relationship with $R^{2}=0.9801$ for PCT and 0.9873 for CRP. Both of the intra- and inter-coefficients of variation for PCT or CRP were within $10 \%$, and the comparison of our method with CLIA showed good consistency. In conclusion, the performance parameters of the dual UPT-LFA method meet the requirements of clinical testing which has great medical application potential in the detection of PCT and CRP. ${ }^{45}$ Further work should be carried out to discover economical and user-friendly multiple detection methods.

\section{Acknowledgements}

This work was founded by the National Natural Science Foundation of China (No. 21176124). All of the monoclonal antibodies of PCT and CRP as well as the serum samples were kindly provided by the Nanjing Norman Biological Technology Co., Ltd.

\section{Supporting Information}

This material is available free of charge on the Web at http:// www.jsac.or.jp/analsci/.

\section{References}

1. J. R. Gilsdorf, J. Pediatr., 2012, 160, 173.

2. M. Şirinoğlu, A. Soysal, A. Karaaslan, E. K. Kadayifci, N. Yalındağ-Öztürk, İ. Cinel, A. Yaman, G. Haklar, Ö. Şirikci, S. Turan, G. A. Gelmez, G. Söyletir, and M. Bakır, J. Infect. Chemother., 2017, 23, 17.

3. D. Thompson, M. B. Pepys, and S. P. Wood, Structure, 1999, 7, 169.

4. A. Ticinesi, F. Lauretani, A. Nouvenne, E. Porro, G. Fanelli, M. Maggio, and T. Meschi, Eur. J. Intern. Med., 2016, 37, 7.

5. M. D. Giudice and S. W. Gangestad, Brain, Behav., Immun., 2018, 70, 61 .

6. M. Barati, F. Alinejad, M. A. Bahar, M. S. Tabrisi, A. R. Shamshiri, N. Bodouhi, and H. Karimi, Burns, 2008, 34,
770.

7. L. J. Deftos, B. A. Roos, and J. G. Parthemore, West. J. Med., 1975, 123, 447.

8. P. Dandona, D. Nix, M. F. Wilson, A. Aljada, J. Love, M. Assicot, and C. Bohuon, J. Clin. Endocrinol. Metab., 1994, $79,1605$.

9. H. L. Huang, X. Nie, B. Cai, J. T. Tang, Y. He, Q. Miao, H. L. Song, T. X. Luo, B. X. Gao, L. L. Wang, and G. X. Li, PLoS One, 2013, 8, e82250.

10. R. Y. Xu, H. W. Liu, J. L. Liu, and J. H. Dong, BMC Urol., 2014, 14, 45.

11. J. Garnacho-Montero, M. J. Huici-Moreno, A. GutiérrezPizarraya, I. López, J. A. Márquez-Vácaro, H. Macher, J. M. Guerrero, and A. Puppo-Moreno, Crit. Care, 2014, 18, R116.

12. J. Jämsä, T. Ala-Kokko, V. Huotari, P. Ohtonen, E. R. Savolainen, and H. Syrjälä, J. Crit. Care, 2018, 43, 139.

13. P. Schuetz, W. Albrich, and B. Mueller, Bmc Med., 2011, 9 , 107.

14. M. Algarra, D. Gomes, and J. C. Esteves da Silva, Clin. Chim. Acta, 2013, 415, 1.

15. M. Rieger, C. Kochleus, D. Teschner, D. Rascher, A. K. Barton, A. Geerlof, E. Kremmer, M. Schmid, A. Hartmann, and H. Gehlen, Anal. Bioanal. Chem., 2014, 406, 5507.

16. S. K. Vashist, G. Czilwik, T. van Oordt, F. von Stetten, R. Zengerle, E. Marion Schneider, and J. H. Luong, Anal. Biochem., 2014, 456, 32.

17. S. Jampasa, W. Siangproh, R. Laocharoensuk, T. Vilaivan, and O. Chailapakul, Talanta, 2018, 183, 311.

18. W. J. Shen, Y. Zhuo, Y. Q. Chai, Z. H. Yang, J. Han, and R. Yuan, ACS Appl. Mater. Interfaces, 2015, 7, 4127.

19. F. Wang and X. Liu, Chem. Soc. Rev., 2009, 38, 976.

20. M. Hao, P. Zhang, B. Li, X. Liu, Y. Zhao, H. Tan, C. Sun, X. Wang, X. Wang, H. Qiu, D. Wang, B. Diao, H. Jing, R. Yang, B. Kan, and L. Zhou, PLoS One, 2017, 12, e0179937.

21. N. A. Taranova, A. N. Berlina, A. V. Zherdev, and B. B. Dzantiev, Biosens. Bioelectron., 2015, 63, 255.

22. M. You, M. Lin, Y. Gong, S. Wang, A. Li, L. Ji, H. Zhao, K. Ling, T. Wen, Y. Huang, D. Gao, Q. Ma, T. Wang, A. Ma, X. Li, and F. Xu, ACS Nano, 2017, 11, 6261.

23. Z. Chen, R. Liang, X. Guo, J. Liang, Q. Deng, M. Li, T. An, T. Liu, and Y. Wu, Biosens. Bioelectron., 2017, 91, 60.

24. Z. Liang, X. Wang, W. Zhu, P. Zhang, Y. Yang, C. Sun, J. Zhang, X. Wang, Z. Xu, Y. Zhao, R. Yang, S. Zhao, and L. Zhou, ACS Appl. Mater. Interfaces, 2017, 9, 3497.

25. X. Qi, Y. Huang, Z. Lin, L. Xu, and H. Yu, Nanoscale Res. Lett., 2016, 11, 167 .

26. V. Kale, T. Soukka, J. Hölsä, and M. Lastusaari, J. Nanopart. Res., 2013, 15, 1850.

27. H. X. Mai, Y. W. Zhang, L. D. Sun, and C. H. Yan, J. Phys. Chem. C, 2007, 111, 13721.

28. L. Lei, J. Zhu, G. Xia, H. Feng, H. Zhang, and Y. Han, Talanta, 2017, 162, 339.

29. Z. Chen, H. Chen, H. Hu, M. Yu, F. Li, Q. Zhang, Z. Zhou, T. Yi, and C. Huang, J. Am. Chem. Soc., 2008, 130, 3023.

30. D. Kumar, K. Verma, S. Verma, B. Chaudhary, S. Som, V. Sharma, V. Kumar, and H. C. Swart, Phys. B, 2018, 535, 278.

31. G. S. Yi and G. M. Chow, Chem. Mater, 2007, 19, 341.

32. E. Palo, L. Pihlgren, M. Tuomisto, T. Laihinen, I. Hyppänen, J. Kankare, M. Lastusaari, T. Soukka, H. C. Swart, and J. Hölsä, Opt. Mater., 2016, 59, 49.

33. J. Tang, L. Lei, H. Feng, H. Zhang, and Y. Han, J. Fluoresc., 2016, 26, 2237.

34. Z. Li and Y. Zhang, Nanotechnology, 2008, 19, 345606. 
35. L. Wang, R. Yan, Z. Huo, L. Wang, J. Zeng, J. Bao, X. Wang, Q. Peng, and Y. Li, Angew. Chem., Int. Ed. Engl., 2005, 44, 6054.

36. Y. Zhao, C. Zhou, R. Wu, L. Li, H. Shen, and L. S. Li, RSC Adv., 2015, 5, 5988

37. Y. Bao, Q. N. Luu, C. Lin, J. M. Schloss, P. S. May, and C. Jiang, J. Mater. Chem., 2010, 20, 8356.

38. L. Wang, R. Yan, Z. Huo, L. Wang, J. Zeng, J. Bao, X. Wang, Q. Peng, and Y. Li, Angew. Chem., Int. Ed., 2005, 44, 6054.

39. S. Wilhelm, M. Kaiser, C. Würth, J. Heiland, C. C. Carrion, V. Muhr, O. S. Wolfbeis, W. J. Parak, U. R. Genger, and T.
Hirsch, Nanoscale, 2015, 7, 1403.

40. U. Sauer, P. Domnanich, and C. Preininger, Anal. Biochem., 2011, 419, 46.

41. P. Buchegger and C. Preininger, Anal. Chem., 2014, 86, 3174.

42. R. Wu, S. Zhou, T. Chen, J. Li, H. Shen, Y. Chai, and L. S. Li, Anal. Chim. Acta, 2018, 1008, 1.

43. H. Li, Y. Sun, J. Elseviers, S. Muyldermans, S. Liu, and Y. Wan, Analyst, 2014, 139, 3718.

44. J. Hao, L. Li, F. Tian, and H. Zhang, Int. J. Ophthalmol., 2016, 9, 292.

45. P. Hausfater, Med. Mal. Infect., 2014, 44, 139. 